\title{
Cross-year peer tutoring on internal medicine wards: results of a qualitative focus group analysis
}

This article was published in the following Dove Press journal:

Advances in Medical Education and Practice

23 September 2014

Number of times this article has been viewed

\author{
Markus Krautter ${ }^{1}$ \\ Sven Andreesen ${ }^{2}$ \\ Nadja Köhl-Hackert ${ }^{3}$ \\ Katja Hoffmann² \\ Wolfgang Herzog ${ }^{2}$ \\ Christoph Nikendei ${ }^{2}$ \\ 'Department of Nephrology, \\ University of Heidelberg, \\ ${ }^{2}$ Department of General Internal \\ Medicine and Psychosomatics, \\ University of Heidelberg Medical \\ Hospital, ${ }^{3}$ Department of General \\ Practice and Health Services \\ Research, University Hospital \\ Heidelberg, Heidelberg, Germany
}

Correspondence: Christoph Nikendei Department of General Internal Medicine and Psychosomatics, University of Heidelberg Medical Hospital, Im Neuenheimer Feld 4I0,

69120 Heidelberg, Germany

$\mathrm{Tel}+49622 I 5638663$

Fax +49622I 565749

Email christoph.nikendei@med.uni-

heidelberg.de
Background: Peer-assisted learning (PAL) has become a well-accepted teaching method within medical education. However, descriptions of on-ward PAL programs are rare. A focus group analysis of a newly established PAL program on an internal medicine ward was conducted to provide insights into PAL teaching from a student perspective.

Purpose: To provide insights into students' experiences regarding their on-ward training with and without accompanying PAL tutors.

Methods: A total of $\mathrm{N}=168$ medical students in their sixth semester participated in the investigation (intervention group: $\mathrm{N}=88$; control group: $\mathrm{N}=80$ ). The intervention group took part in the PAL program, while the control group received standard on-ward training. There were seven focus groups with $\mathrm{N}=43$ participants (intervention group: four focus groups, $\mathrm{N}=28$ participants; control group: three focus groups, $\mathrm{N}=15$ participants). The discussions were analyzed using content analysis.

Results: The intervention group emphasized the role of the tutors as competent and well-trained teachers, most beneficial in supervising clinical skills. Tutors motivate students, help them to integrate into the ward team, and provide a non-fear-based working relationship whereby students' anxiety regarding working on ward decreases. The control group had to rely on autodidactic learning strategies when neither supervising physicians nor final-year students were available. Conclusion: On-ward PAL programs represent a particularly valuable tool for students' support in training clinical competencies on ward. The tutor-student working alliance acts through its flat hierarchy. Nevertheless, tutors cannot represent an adequate substitute for experienced physicians.

Keywords: peer-assisted learning, cross-year peer tutoring, undergraduate medical education, final year, internal medicine, clinical skills training

\section{Background}

Peer-assisted learning (PAL) has become an established and well-accepted teaching method in medical education, ${ }^{1,2}$ which offers a variety of advantages both for learners ${ }^{2}$ and for peer tutors. ${ }^{3,4}$ PAL is a voluntary relationship between the tutor and the trainee that provides challenge, growth, and motivation to develop professional, collegial skills. This relationship is multifaceted; tutors take on the roles of advisor, advocate, teacher, active listener, and friend. ${ }^{5}$ In this respect, PAL encompasses the opportunity to encourage more positive attitudes towards learning and may increase the students' enthusiasm for learning in general. ${ }^{2,6}$ Since student tutors have had the same learning experiences, they are able to understand why the trainees may have difficulties. ${ }^{2}$ One of the major benefits of PAL is the informality that junior students 
feel towards more senior students. This informality allows students to raise areas of concern without feeling foolish or concerned about ridicule due to a lack of knowledge or understanding. ${ }^{7}$ This teaching approach likewise brings advantages for the tutor. Tutors can develop their teaching skills ${ }^{8}$ or assist students in obtaining a greater understanding of the topics they are teaching. ${ }^{6}$

Positive effects of PAL programs have been demonstrated in controlled studies in the fields of gross anatomy, ${ }^{9}$ problem-based learning, ${ }^{10}$ communication skills training, ${ }^{11}$ clinical examination, ${ }^{12}$ and resuscitation training. ${ }^{13}$ For the teaching of clinical technical skills, Tolsgaard et al ${ }^{14}$ and Weyrich et $\mathrm{al}^{15}$ demonstrated that trained student tutors can be equally as effective as associate professors. Despite these promising results, the differential effects that account for the effectiveness of PAL programs in training clinical skills remain largely in the dark. Moreover, descriptions and evaluations of PAL programs on ward/at the bedside for clinical skills training are rare.

Nikendei et al ${ }^{16,17}$ implemented a cross-year PAL on-ward program at the Medical Hospital of the University of Heidelberg (Heidelberg, Germany) for medical students in their third year of training as part of a randomized controlled trial. This program was developed in line with recommendations made by Wadoodi and Crosby ${ }^{7}$ and Ross and Cameron, ${ }^{18}$ and included ten patient-centered tutorials. The evaluation of the on-ward PAL program showed high acceptance ratings by both medical students and PAL tutors. Trainees reported that they felt significantly more integrated on the wards and experienced less anxiety concerning future on-ward work as a medical doctor compared to controls. ${ }^{17}$ Furthermore, selfassessed competencies of the trainees improved significantly in skills exclusively trained in the PAL program. Peer tutors acknowledged that participating in the course increased their basic clinical skills and enhanced their personal teaching skills. Alford and Currie ${ }^{19}$ described an educational on-ward intervention in which first-year medical students shadowed experienced medical students performing routine clinical duties for 1 day in every 6 weeks over a period of 1 year. The qualitative analysis revealed that through this learning approach, the students gained important insights into the everyday practice of medicine. However, their on-ward intervention cannot be referred to as PAL training in the strict sense, because the tutors were not trained to apply defined didactic methods and to realize clearly defined learning objectives. The investigation by Alford and Currie ${ }^{19}$ also fails to fulfil basic methodological requirements. They did not provide any information about the sample size or the approach of qualitative analysis chosen, and the study design did not include a control group.

In the field of PAL research, the presented study is the first qualitative investigation of trainees' experiences of a PAL program on internal medicine wards. To elucidate underlying causalities behind the results of Nikendei et al, ${ }^{16,17}$ a focus group analysis was conducted to provide further insights into PAL teaching on ward from a student perspective.

\section{Methods}

\section{Sample}

$\mathrm{N}=168$ medical students in their sixth semester voluntarily participated in the investigation. The students were allocated to one of 14 wards at the Medical University Hospital of Heidelberg for 5 weeks. The wards were divided into two comparable groups of seven intervention wards with tutors and seven control wards without tutors. The students were randomly assigned to either an intervention or a control ward. The intervention group $(n=88)$ was composed of 51 female and 37 male students (mean age 23.6 years). The size of the different tutorials ranged from three to eight students. The control group ( $\mathrm{n}=80$ ) was composed of 58 female and 22 male students (mean age 23.2 years). From the student sample, seven focus groups encompassing 43 voluntary participants (intervention group: four focus groups with a total of 28 participants; control group: three focus groups with a total of 15 participants) were formed. Further details are displayed in Table 1.

$\mathrm{N}=14$ final-year medical students (eight females; six males; mean age 26.2 years) volunteered to serve as tutors. They participated in a 6-hour PAL training course, which included specific content of internal medicine, feedback training, and didactic methods to apply as a PAL tutor. The course was led by an experienced clinical educator

Table I Composition of the focus groups conducted with the intervention group $(n=28)$ and control group $(n=15)$

\begin{tabular}{lll}
\hline & $\begin{array}{l}\text { Intervention } \\
\text { group }\end{array}$ & $\begin{array}{l}\text { Control } \\
\text { group }\end{array}$ \\
\hline Focus groups & $\mathrm{n}=4$ & $\mathrm{n}=3$ \\
Participants & $\mathrm{n}=28$ & $\mathrm{n}=15$ \\
Female participants & $\mathrm{n}=15$ & $\mathrm{n}=9$ \\
Male participants & $\mathrm{n}=13$ & $\mathrm{n}=6$ \\
$\begin{array}{l}\text { Age of participants, years } \\
\text { (mean } \pm \text { SD) }\end{array}$ & $23.21 \pm 0.96$ & $23.33 \pm 0.90$ \\
$\begin{array}{l}\text { Duration of the discussions, minutes } \\
\text { (mean } \pm \text { SD) }\end{array}$ & $55 \pm 3.16$ & $50 \pm 13.75$ \\
\hline
\end{tabular}

Abbreviation: SD, standard deviation. 
in internal medicine and consisted of lectures, role plays, training related to on-ward topics, and discussion about difficult situations in PAL courses. In addition, the tutors received a tutor manual. Furthermore, a weekly meeting with a consultant was held in order to discuss upcoming problems during the PAL courses, organizational issues, and to prepare for the next courses. The tutors were recompensed with 150 Euro for their participation. At the time of the study, untrained final-year students were also working on the control wards.

\section{PAL on-ward program}

The PAL on-ward program included patient-centered tutorials (duration: 1.5 hours each) held twice a week by the tutors on the intervention wards. The learning objectives focused on the following clinical skills: history taking, developing a patientcentered attitude, physical examinations, drawing blood/ applying indwelling catheters, infusion/blood transfusion, completing patient files, electrocardiogram writing, and chart rounds. ${ }^{16}$ The tutorials primarily took place at the bedside.

\section{Internal medicine curriculum at the University of Heidelberg}

On-ward, medical students in both the intervention group and the control group had to achieve a total of 50 credit points within a credit scoring system (eg, application of indwelling catheter $=$ one point) over the course of the semester. In addition to their on-ward activities, all students attended symptom-oriented lectures, daily small-group seminars for internal medicine subspecialties, lessons in problem-based learning, ${ }^{20}$ skills lab training, ${ }^{21}$ and communication training with standardized patients. ${ }^{22}$

\section{Focus group interviews}

The aim of the focus group interviews was to explore the subjective perception, judgment, and experience of medical students with regard to their on-ward training with (intervention group) and without (control group) PAL teaching. ${ }^{23,24}$ The number of focus groups resulted from a content saturation in the discussions, ie, for the generation of new content aspects, a new focus group was opened until the content saturation point was reached. ${ }^{25}$ The groups were composed as shown in Table 1. Each focus group discussion was based on the following "question route":

- Question 1: What kind of skills have you learned on ward and what positive or negative experiences did you have?
- Question 2: How did you experience your support on ward? Who supported you? What was helpful about it? What was not helpful?

The discussions were recorded and subsequently transcribed.

\section{Analysis of the transcripts}

After transcribing the audio files of the peer tutor interviews verbatim, a qualitative content analysis was performed following the principles of grounded theory. First, an open coding of all of the interview transcriptions was conducted line by line. In detail, single or few sentences were identified as a code, representing the most elemental unit of meaning. Next, the codes were summarized into relevant themes for each participant, using the software MAXQDA (2010 version; VERBI GmbH, Berlin, Germany). As themes were recurrent among different participants, themes were then compared and adapted until relevant themes for all participants could be defined. The assignment of respective codes to specific themes was conducted by two independent analyzers and subsequently discussed to reach consensus and, if required, adjusted. The analyzers ( $\mathrm{SA}$ and $\mathrm{CN}$ ) both have expertise in qualitative research and are also certified skills lab trainers. In a final step, themes were consolidated into relevant categories.

\section{Ethics}

The ultimate goal of the study was curriculum improvement. Consequently, the ethics committee of the University of Heidelberg waived the requirement for an ethical approval procedure for the above described study design. The study was conducted in accordance to the Declaration of Helsinki (revised form, Seoul, 2008). All participants gave written informed consent. Study participation was voluntary.

\section{Results \\ Main categories and topics}

Within the structured focus group discussions, a total of 480 relevant individual statements were detected (intervention group: 201 individual statements; control group: 279 individual statements). From these, main categories were derived for the intervention group (on-ward training with PAL tutor) for trainees and for the control group (on-ward training without PAL tutor):

- Main categories - intervention group: 
Table 2 Example student quotations in the focus groups for the intervention group - main category A: experiences of the trainees with the role of tutor

\section{Intervention group - main category A}

\section{Al Tutor supports trainees}

Quotation: "The final-year student did it really great. He always asked really nicely if you went up to him again. So, what can I do for you? Shall I show you something else?"

A2 Tutor motivates trainees

Quotation: "The tutors were always very committed."

A3 Tutor integrates trainees

Quotation: "The fact that you have someone on ward whom you can

ask, someone who holds your hand a bit, and introduces you to things

a bit, because after all, it's the first time for most people."

A4 Tutor supervises trainees

Quotation: "There were three final-year students. They just watched.

Then they told us what we'd done well, what we could have done

better. I found that really pleasant."

A5 Tutor enables informal learning relationship

Quotation: "The final-year students are a bit like fellow sufferers, which I liked. That made it easier for me. It's just much more collegial."

A6 Tutor convinces through competence

Quotation: "Were always well prepared."
A. Trainees' experiences with the role of the tutor (see example quotations in Table 2)
B. Trainees' experiences with the PAL tutorial (see example quotations in Table 3)
- Main categories - control group:

Table 3 Example student quotations in the focus groups for the intervention group - main category $B$ : experiences of trainees with the peer-assisted learning tutorial

\footnotetext{
Intervention group - main category B

BI Tutorial contains meaningful learning contents

Quotation: "Then we learned a lot about presenting a patient and it was fairly structured. I found that good. One time we also spent a whole

hour writing and deriving results of electrocardiograms, which was also really good I think. And we did drawing blood well."

B2 Tutorial contains supportive didactic material

Quotation: "I found that very good. It's really helpful. It's just so brief and succinct; once you'd talked it through, it was just clear."

B3 Tutorial structures the ward placement

Quotation: "I found that very good with the final-year tutor, also because you had a program where you knew what you were doing the whole day." B4 Tutorial fosters patient contacts

Quotation: "We were really over $50 \%$ of the time in the room and with the patient."

B5 Voluntary nature of the tutorial

Quotation: "But also the fact that you don't have to go even if you can." B6 Group sizes within the tutorial

Quotation: "It would probably be even more beneficial to have even smaller groups."

B7 Acceptance of the tutorial by the physicians

Quotation: "I also had the feeling that the ward physicians disapproved of the tutorial a bit."
}

Table 4 Example student quotations in the focus groups for the control group - main category C: experiences of the trainees on ward without the peer-assisted learning tutorial

\section{Control group - main category $\mathbf{C}$ \\ CI Consolidation of clinical-practical skills \\ Quotation: "I have already learned the most important types of examination. History taking, physical examination, also drawing blood, putting in lines, also dealing with infusions and electrocardiogram." C2 Supervision by physicians on ward}

Quotation: "l'd also like to say something positive about it now: one day, when we had our internal case report, a senior physician came, who by the way was not on this ward, and she gave up a lot of her time. And I also learned a lot in a very short time."

C3 Student integration and acceptance on ward

Quotation I: "A lot is down to taking the initiative. At the beginning, you had to get on people's nerves and then they knew what we wanted. Then they also came to us."

Quotation 2: "At the beginning I had the feeling I was an additional burden. That's daft when you think that the teaching should have a really great importance and you have the feeling when you go into the ward room that he thinks: oh God, not another student to rob me of my time." C4 Practical orientation of the ward placement

Quotation: "The only thing that we taught ourselves was practising history taking and physical examination."

C5 Consideration of students' prior knowledge

Quotation: "It would be better if the ward physicians knew what we already know (eg that we had an percussion examination course) and what we should learn."

\section{C6 Preparation for the practical year}

Quotation: "You had the feeling you had to be as far along as you are before the final year with the practical skills in internal medicine. In this respect I find it really shocking because it is a quite practically oriented concept in Heidelberg."

C. Trainees' experiences with their on-ward training without the PAL tutorial (see example quotations in Table 4)

D. Trainees' experiences with the final-year students on ward (see example quotations in Table 5).

\section{Intervention group}

Within the main two categories of the intervention group, a total of 14 subtopics were identified. These are defined in the following sections.

\section{Intervention group - main category A: trainees'} experiences with the role of the tutor

\section{- A1 Tutor supports trainees}

Definition: The tutor supports the trainees, ie, he helps them with concrete concerns through practical help (eg, assigning patients for patient reports) as well as information, and he supports them through his presence, enabling the students to feel secure on ward.

- A2 Tutor motivates trainees 
Table 5 Example student quotations in the focus groups for the control group - main category D: experiences of the trainees with the final-year students

\begin{tabular}{l}
\hline Control group - main category D \\
\hline DI Support by final-year students \\
Quotation: “Then we had a really inopportune moment. At least before \\
we came there were final-year students there, and the moment we came \\
there weren't." \\
D2 Instruction by final-year students \\
Quotation: "You did have to work it out very independently. The \\
teaching was relatively negative. You had to be really insistent before you \\
got anybody at all to show you something. There was really relatively \\
little place for teaching. We were simply left to our own devices a bit. \\
Because of this we had no supervision, no guidance. It was just a bit \\
difficult, but well, if you do it often, you do learn it." \\
D3 Trainees learn in an autodidactic manner \\
Quotation: "What we taught ourselves was practising history taking \\
and physical examination. But there we did it as we knew it from the \\
examination course, or just left it."
\end{tabular}

Definition: The tutor influences the trainees through his personality, his enthusiasm, and his dynamism. This motivates the trainees to actively get to know the ward, to assume ward tasks, and to look after their own patients.

- A3 Tutor integrates trainees

Definition: The tutor mediates between trainees and physicians as well as between trainees and care personnel. This integrates the trainees into the ward and into the ward team. Consequently, the trainees are frequently able to take part in examinations and have sufficient patient contacts.

- A4 Tutor supervises trainees

Definition: The tutor observes the trainees in the implementation of clinical-practical skills on ward and gives them constructive feedback.

- A5 Tutor enables informal learning relationship Definition: The trainees feel more free and uninhibited towards their tutor than towards ward and senior physicians. Due to the nonhierarchical relationship, they feel understood.

- A6 Tutor convinces through competence

Definition: The tutor appears well trained and prepared (eg, he is familiar with the work materials used), and he convinces the trainees through his competence.

\section{Intervention group - main category B: trainees'} experiences with the PAL tutorial

- B1 Tutorial contains meaningful learning contents Definition: The trainees are trained in relevant clinicalpractical skills and competencies (eg, history taking, setting up electrocardiograms, electrocardiogram findings, and physical examination).

- B2 Tutorial contains supportive didactic material

Definition: Didactic material (eg, handouts) supports the trainees in regards to content and structure of ward placement. Learning content can be reworked.

- B3 Tutorial structures the ward placement

Definition: The tutorial provides the trainees with a meaningful structure for their daily routine on ward.

- B4 Tutorial fosters patient contacts

Definition: The tutorial provides a suitable framework for supervised patient contacts and fosters the involvement of students in examinations at the patients' bedside.

- B5 Voluntary nature of the tutorial

Definition: Tutorials on a voluntary basis enable the trainees to decide on the content which they deem to be relevant to them and can be better reconciled with the general timetable.

- B6 Group sizes within the tutorial

Definition: Small group sizes in the tutorial offer the trainees a concentrated learning environment and better learning effects. Through small group sizes, the patients are not over-challenged.

- B7 Acceptance of the tutorial by the physicians

Definition: The acceptance of the tutorial and the deployment of the final-year students as trainees support the learning success of the PAL program as a whole.

\section{Control group}

Within the two main categories of the control group, a total of nine subtopics were identified. These are defined in the following sections.

\section{Control group - main category C: trainees' experiences with their on-ward training without PAL tutorial}

- C1 Consolidation of clinical-practical skills

Definition: On-ward, important basic medical skills such as history taking and physical examination are trained.

- C2 Supervision by physicians on ward

Definition: Ward physicians and senior physicians who are able to take time to supervise and guide the trainees are indispensable for students' learning success. Respectful relations and flat hierarchical relationships are very conducive to anxiety-free learning processes.

- C3 Student integration and acceptance on ward 
Definition: For students' learning success, the active and respectful integration of the trainees on ward is a fundamental prerequisite. In this regard, the attitude of both the physicians and the care personnel plays a decisive role in appropriately conveying to the trainees the importance and acceptance of their training on ward.

- C4 Practical orientation of the ward placement

Definition: The students' ward placement provides a framework for promoting the practical orientation of medical training. Besides history taking and patient presentation by senior physicians, the intensive training at the patient's bedside is therefore indispensable, which is something that is not always sufficiently guaranteed.

- C5 Consideration of students' prior knowledge

Definition: In order to avoid either under- or overchallenging the trainees on ward, the supervising physicians should be aware of and take into consideration students' prior knowledge.

- C6 Preparation for the practical year

Definition: Students' ward placements should have an appropriate emphasis on practical training so that trainees are prepared for their practical year.

\section{Control group - main category D: trainees' experiences with the final-year students on ward}

- D1 Support by final-year students

Definition: Final-year students on ward support the trainees when there is an opportunity to do so and when the final-year students are not being utilized elsewhere. Individual final-year students offer the trainees active help.

- D2 Instruction by final-year students

Definition: Final-year students compensate in part for the lack of supervision of the trainees by physicians on ward and instruct the trainees in the different medical competencies and skills (eg, how to draw blood properly).

- D3 Trainees learn in an autodidactic manner

Definition: The trainees learn and mutually support each other when no guidance and supervision is available from physicians or from final-year students.

\section{Discussion}

The current qualitative study allows an indepth analysis of a PAL program for undergraduate medical students on internal medicine wards with final-year students serving as peer tutors. The focus groups shed light on the role of the tutor and the makings of a successful tutor-trainee relationship. Regarding the role of the ward physicians, positive and negative aspects of the physician-student working alliance were detected. Furthermore, the presented on-ward PAL program shows an effective structuring for workplace learning - a key challenge of clinical rotations.

In the presented PAL on-ward program, trainees perceived tutors as competent and well-trained teachers, most beneficial in supervising clinical skills. The results confirm the findings of quantitative studies using controlled designs that demonstrated professional competence of PAL tutors in terms of instructing and training clinical-technical skills in different fields of medicine. ${ }^{9,11,13-15,26,27}$ Additionally, the focus groups revealed that on-ward PAL tutors provide orientation and facilitate students' integration on ward. These results are in line with a quantitative evaluation of the described program emphasizing the importance of the PAL tutor as teacher, contact person, and integration figure. ${ }^{28}$ But most importantly, qualitative results show that PAL tutors motivate the students and help them to develop self-assurance, which might explain the reduction of students' anxiety regarding working on ward. This was also detected in previous research. ${ }^{17}$ The reduction of anxiety might be crucial for students in order to have the courage to assume independent patient management - one of the most central learning goals of workplace learning. All of these aspects constitute important characteristics of the tutortrainee working alliance and have been shown to be likewise relevant for other areas of work in the medical field. ${ }^{5}$

To the authors' surprise, in this qualitative analysis, the physician-student relationship was only marginally mentioned by the intervention group. This is all the more astonishing as an accompanying quantitative evaluation showed better integration on ward for the intervention group than for the control group. ${ }^{17}$ However, students' reports on their on-ward experience revealed that $68 \%$ of the control group had contact with the ward physician versus only $40 \%$ of the intervention group (unpublished data). This is an alarming finding, as clinical rotations cannot only rely on PAL programs. Trainees on ward need experienced physicians to deliver higher level competencies such as clinical reasoning skills. Clinical reasoning expertise and professionalism evolve through repetitive practical experience and casebased reflection, as it has been described in the literature. ${ }^{29-32}$ Experienced members of the postgraduate staff serve as models for professionalism ${ }^{33}$ and are competent coaches for case-based reflections. ${ }^{34}$ Student-physician training is therefore definitively necessary to develop medical expertise. In line with this fact, the control group does emphasize the role of the ward physicians and senior physicians for their learning success. There is a need for a respectful, 
supportive physician-student relationship that is not based on fear. The students' preexisting clinical competence level should be properly recognized by the physicians. Here, an important interplay between ward physicians and tutors could be established, in which students benefit from ward physicians' clinical experience. Student tutors, on the other hand, represent an important link between ward physicians and students based on their competence to integrate and due to the flat hierarchy between students and tutors, which is not based on fear. Otherwise, students - as shown by the control group - have to completely reply on ward physicians' or the nursing staff's willingness to integrate them into the ward team. As the control group reports, if students do not have sufficient contact either with ward physicians or with final-year students, they are left on their own and are forced to follow autodidactic learning strategies.

Overall, the current study shows the multiple benefits of a PAL program to structure workplace learning on ward. Structuring of clinical placements represents a serious challenge in medical education. Literature shows that clinical rotations are seen more or less as a black box that conveys a trial-and-error method ${ }^{35}$ and fails to provide explicit learning objectives, defined responsibilities, and structured supervision. ${ }^{36-39}$ Most importantly, the PAL on-ward program could be supportive for independent patient management by reducing the anxiety regarding working on ward - which means achieving one of the most important clinical learning objectives. The authors assume that on-ward PAL programs have the potential to structure clinical rotations, an essential prerequisite for successful learning experiences of students on ward.

A limitation of this study is that a selection bias for the interviewed students may have occurred, as only voluntarily participating students took part in the focus group interviews. However, four focus groups were conducted for the intervention group, and three focus groups for the control group, with a total of 43 participants. As the number of focus groups depended on a content saturation in the discussions, ie, for the generation of new content aspects, a new focus group was opened until the content saturation point was reached, ${ }^{25}$ it is assumed that most of the relevant students' experiences were depicted by this qualitative approach. Students' individual subjective experiences may overshadow more representative aspects from a quantitative perspective. Nevertheless, the accompanying evaluation ${ }^{16}$ showed a high concordance with the qualitative results presented in this study. Qualitative research allows a more indepth analysis of on-ward learning experiences.

\section{Conclusion}

Statements by the interviewed students point toward the PAL program being a valuable tool for supporting them in the training of clinical competencies on ward, given that a suitable structure, successful integration into the ward team, and student supervision is rare. The essence of the student-tutor relationship observed in other fields of education is confirmed for PAL on-ward programs. Nevertheless, it is crucial to develop physician-student working alliances on ward, as an on-ward PAL program cannot represent a substitute of equal worth. Further research is needed to confirm and clarify how PAL tutors should be trained to fulfil their teaching role in an adequate manner and which components make PAL on-ward training most effective.

\section{Acknowledgments}

This study was supported by the Ministry of Science, Research, and Arts, Baden-Württemberg, Germany. Project identification number: D 100011720; AZ32-402.17(05)/34 The funding body did not have an influence on the study design, collection, analysis, and interpretation of presented data, writing of the manuscript, or the decision to submit the manuscript for publication. Financial support was also received from Deutsche Forschungsgemeinschaft and Ruprecht-Karls-Universität Heidelberg within the funding program Open Access Publishing.

MK conceived of the study, participated in the design of the study, analyzed the data, and drafted the manuscript. SA performed the focus group interviews and helped carry out the qualitative analysis. NKH helped design and coordinate the study and supervised the peer-assisted learning program. $\mathrm{KH}$ helped design and coordinate the study and supervised the peer-assisted learning program. WH participated in designing the study and helped to draft the manuscript. $\mathrm{JJ}$ participated in designing the study and helped to draft the manuscript. CN conceived of the study, participated in its design, and helped to draft the manuscript. All authors read and approved the final manuscript.

\section{Disclosure}

The authors report no conflicts of interest in this work.

\section{References}

1. Ten Cate O, Durning S. Peer teaching in medical education: 12 reasons to move from theory to practice. Med Teach. 2007;29(6):591-599.

2. Santee J, Garavalia L. Peer tutoring programs in health professions schools. Am J Pharm Educ. 2006;70(3):70.

3. Dandavino M, Snell L, Wiseman J. Why medical students should learn how to teach. Med Teach. 2007;29(6):558-565. 
4. Sobral DT. Cross-year peer tutoring experience in a medical school: conditions and outcomes for student tutors. Med Educ. 2002;36(11):1064-1070.

5. Ramsey P, Blowers S, Merriman C, Glenn LL, Terry L. The NURSE Center: a peer mentor-tutor project for disadvantaged nursing students in Appalachia. Nurse Educ. 2000;25(6):277-281.

6. Clarke B, Feltham W. Facilitating peer group teaching within nurse education. Nurse Educ Today. 1990;10(1):54-57.

7. Wadoodi A, Crosby JR. Twelve tips for peer-assisted learning: a classic concept revisited. Med Teach. 2002;24(3):241-244.

8. Carroll M. Peer tutoring: can medical studies teach biochemistry? Biochem Educ. 1996;24(1):13-15.

9. Nnodim JO. A controlled trial of peer-teaching in practical gross anatomy. Clin Anat. 1997;10(2):112-117.

10. Kassab S, Abu-Hijleh MF, Al-Shboul Q, Hamdy H. Student-led tutorials in problem-based learning: educational outcomes and students' perceptions. Med Teach. 2005;27(6):521-526.

11. Nestel D, Kidd J. Peer assisted learning in patient-centred interviewing: the impact on student tutors. Med Teach. 2005;27(5):439-444.

12. Field M, Burke JM, McAllister D, Lloyd DM. Peer-assisted learning: a novel approach to clinical skills learning for medical students. Med Educ. 2007;41(4):411-418.

13. Perkins GD, Hulme J, Bion JF. Peer-led resuscitation training for healthcare students: a randomised controlled study. Intensive Care Med. 2002;28(6):698-700.

14. Tolsgaard MG, Gustafsson A, Rasmussen MB, Hoiby P, Muller CG, Ringsted C. Student teachers can be as good as associate professors in teaching clinical skills. Med Teach. 2007;29(6):553-557.

15. Weyrich P, Celebi N, Schrauth M, Moltner A, Lammerding-Koppel M, Nikendei C. Peer-assisted versus faculty staff-led skills laboratory training: a randomised controlled trial. Med Educ. 2009;43(2): 113-120.

16. Nikendei C, Andreesen S, Hoffmann K, Junger J. Cross-year peer tutoring on internal medicine wards: effects on self-assessed clinical competencies - a group control design study. Med Teach. 2009;31(2):e32-e35.

17. Nikendei C, Kohl-Hackert N, Junger J. Peer-assisted learning: a planning and implementation framework. Guide supplement 30.3-practical application. Med Teach. 2008;30(4):442-443.

18. Ross MT, Cameron HS. Peer assisted learning: a planning and implementation framework: AMEE Guide no 30. Med Teach. 2007; 29(6):527-545.

19. Alford CL, Currie DM. Introducing first-year medical students to clinical practice by having them "shadow" third-year clerks. Teach Learn Med. 2004;16(3):260-263.

20. Huwendiek S, Skelin S, Nikendei C, Bosse HM, Kischfink M. PBL in der medizinischen Ausbildung: Erfahrungen an der Medizinischen Fakultät Heidelberg. [Problem based learning within medical education. Experiences at the Medical Faculty of the University of Heidelberg]. In: Zumbach J, Weber A, Olsowski G, editors. Problembasiertes Lernen: Konzepte, Werkzeuge und Fallbeispiele aus dem deutschsprachigen Raum. Bern: h.e.p. Verl; 2007:147-159. German.

21. Nikendei C, Zeuch A, Dieckmann P, et al. Role-playing for more realistic technical skills training. Med Teach. 2005;27(2):122-126.
22. Schultz JH, Schonemann J, Lauber H, Nikendei C, Herzog W, Junger J. Einsatz von Standardisierten Patienten im Kommunikations- und Interaktionstraining für Medizinstudierende (Medi-KIT): Bedarfsanalyse - Training-Perspektiven. [Standardized Patients in Communication- and Interaction Training for undergraduate medical students (Medi-KIT): Needs assessment - training - perspectives]. Zeitschrift für Gruppendynamik und Organisationsberatung. 2007;38(1):7-23. German.

23. Krueger RA, Casey MA. Focus Groups: A Practical Guide for Applied Research. Thousand Oaks, CA: Sage; 2000.

24. Przyborski A, Wohlrab-Sahr M. Qualitative Sozialforschung. Ein Arbeitsbuch. [Qualitative social science resarch. A workbook]. München: Oldenburg Verlag; 2009. German.

25. Rabiee F. Focus-group interview and data analysis. Proc Nutr Soc. 2004;63(4):655-660.

26. Haist SA, Wilson JF, Fosson SE, Brigham NL. Are fourth-year medical students effective teachers of the physical examination to firstyear medical students? J Gen Intern Med. 1997;12(3):177-181.

27. Steele DJ, Medder JD, Turner P. A comparison of learning outcomes and attitudes in student- versus faculty-led problem-based learning: an experimental study. Med Educ. 2000;34(1):23-29.

28. Nikendei C, Andreesen S, Hoffmann K, Obertacke U, Schrauth M, Junger J. [Final-year medical students as tutors for undergraduate students during their on-ward courses in internal medicine: a quantitative analysis]. Z Evid Fortbild Qual Gesundhwes. 2008;102(10):654-661. German.

29. Rochmawati E, Wiechula R. Education strategies to foster health professional students' clinical reasoning skills. Nurs Health Sci. 2010;12(2):244-250.

30. Mylopoulos M, Regehr G. Cognitive metaphors of expertise and knowledge: prospects and limitations for medical education. Med Educ. 2007;41(12):1159-1165.

31. Zink T, Halaas GW, Brooks KD. Learning professionalism during the third year of medical school in a 9-month clinical rotation in rural Minnesota. Med Teach. 2009;31(11):1001-1006.

32. Elliott DD, May W, Schaff PB, et al. Shaping professionalism in pre-clinical medical students: professionalism and the practice of medicine. Med Teach. 2009;31(7):e295-e302.

33. Howe A. Twelve tips for developing professional attitudes in training. Med Teach. 2003;25(5):485-487.

34. Kassirer JP. Teaching clinical reasoning: case-based and coached. Acad Med. 2010;85(7):1118-1124.

35. Jolly BC, Macdonald MM. Education for practice: the role of practical experience in undergraduate and general clinical training. Med Educ. 1989;23(2):189-195.

36. Remmen R, Denekens J, Scherpbier A, et al. An evaluation study of the didactic quality of clerkships. Med Educ. 2000;34(6):460-464.

37. Remmen R, Derese A, Scherpbier A, et al. Can medical schools rely on clerkships to train students in basic clinical skills? Med Educ. 1999;33(8):600-605.

38. Van Der Hem-Stokroos HH, Scherpbier AJ, Van Der Vleuten CP, De Vries H, Haarman HJ. How effective is a clerkship as a learning environment? Med Teach. 2001;23(6):599-604.

39. Prideaux D, Alexander H, Bower A, et al. Clinical teaching: maintaining an educational role for doctors in the new health care environment. Med Educ. 2000;34(10):820-826.
Advances in Medical Education and Practice

\section{Publish your work in this journal}

Advances in Medical Education and Practice is an international, peerreviewed, open access journal that aims to present and publish research on Medical Education covering medical, dental, nursing and allied health care professional education. The journal covers undergraduate education, postgraduate training and continuing medical education including emerging trends and innovative models linking education, research, and health care services. The manuscript management system is completely online and includes a very quick and fair peer-review system. Visit http://www.dovepress.com/testimonials.php to read real quotes from published authors. 